[Agr. Biol. Chem. Vol. 30, No. 9, p. 835 840, 1966]

\title{
Respiration in Organic Acid-Forming Molds
}

\section{Part III. Alteration of the Electron Transport System during Lactate Fermentation in Rhizopus oryzae}

\author{
By Akira Ốbayashi and Matsuo Kanie \\ Faculty of Agriculture, Kagoshima University, Kagoshima \\ Received October 15, 1965
}

\begin{abstract}
Mycelia of Rhizopus oryzae, a lactate forming fungus, were used to study respiration and glucose degradation in this organism.

The respiration of the mycelia obtained during an early stage of shake culture growth, when only a little lactate was produced, was completely inhibited by $\mathrm{KCN}$, while the respiration of the mycelia obtained from older shake cultures, or from surface cultures, regardless of the age, was not inhibited by $\mathrm{KCN}$. These results suggest that energy for growth of Rhizopus oryzae is predominantly obtained by a respiratory system involving cytochromes and that a loss of this system occurs in older shake cultures which then begin to accumulate lactate. This observation was confirmed by the enzymatic studies on cell-free extracts.
\end{abstract}

\section{INTRODUCTION}

In the previous paper, ${ }^{1)}$ we reported the contents of cytochrome $c$, flavins and coenzyme $\mathrm{Q}_{\mathrm{g}}$ in the mycelia of lactate forming Rhizopus oryzae. The results showed that the mycelia of shake cultures were rich in cytochrome $c$ and FAD, and lower in FMN than surface culture mycelia. Moreover, the contents of cytochrome $\mathrm{c}$ and $\mathrm{FAD}$ decrease with the progress of the fermentation.

In the present study an attempt was made to determine the respiration of Rhizopus oryzae in order to clarify the reason for the large amount of lactic acid accumulated by the organism under certain aerobic condition.

\section{METHODS}

The microorganism and its cultural conditions were described in the preceding paper.1)

Respiratory quotient and lactate formation by mycelium. Warburg experiments were carried out with glucose as the substrate in order to determine $\mathrm{CO}_{2}$ and $\mathrm{O}_{2}$ balance. The residual glucose and lactate 1) A. Obayashi and M. Kanie, This Journal, 30, 725 (1966). formed were determined by the Somogyi method modified by Kobayashi and Tabuchi ${ }^{2)}$ and the BarkerSummerson method, ${ }^{3)}$ respectively. The rate of oxygen uptake $\left(\mathrm{Qo}_{2}\right)$ was expressed as the volume $(\mu \mathrm{l})$ of oxygen absorbed per mg dried mycelia per hour.

Enzyme activities of cell-free extracts. Washed mycelia were ground with an equal weight of quartz sand in a porcelain mortar, and then suspended in $20 \mathrm{ml}$ of $0.1 \mathrm{~m}$ phosphate buffer ( $\mathrm{pH} 6.8$ ) per $1 \mathrm{~g}$ mycelia (dried weight). The suspension was stirred for 20 minutes in an ice bath and the cell-free extract was obtained by centrifugation at $20,000 \times \mathrm{g}$ for 20 minutes at $0^{\circ} \mathrm{C}$.

To compare the various enzymatic activities of the cell-free extract, the following assay methods were adopted; namely, the method of Racker $^{-4}$ for alcohol dehydrogenase (alcohol: NAD oxidoreductase, EC 1.1.1.1), which was described previously ${ }^{5}$ for L-lactic dehydrogenase (L-lactate : NAD oxidoreductase, EC 1.1.1.27); the method of $\mathrm{Mahler}^{(3)}$ for $\mathrm{NADH}_{2}$-cyto-

2) T. Kobayashi and T. Tabuchi, J. Agr. Chem. Soc. Japan, 28, 171 (1954).

3) S. B. Barker and W. H. Summerson, J. Biol. Chem., 138, 535 (1941).

4) E. Racker, ibid., 184, 313 (1950).

5) A. Obayashi, H. Yorifuji, T. Yamagata, T. Ijichi and M. Kanie, This Journal, 30, 717 (1966).

6) H. R. Mahler, N. K. Sarkar, L. P. Vernon and R. T. Alberty, J. Biol. Chem., 199, 585 (1952). 
chrome c reductase $\left(\mathrm{NADH}_{2}\right.$-cytochrome c oxidoreductase, EC 1.6.2.1); the method of $\mathrm{Smith}^{7)}$ for cytochrome c oxidase (cytochrome $\mathrm{c}: \mathrm{O}_{2}$ oxidoreductase, EC 1.9.3.1); the method of Fukui ${ }^{8)}$ and Mizushima ${ }^{\text {() }}$ for $\mathrm{NADH}_{2}$ peroxidase $\left(\mathrm{NADH}_{2}: \mathrm{H}_{2} \mathrm{O}_{2}\right.$ oxidoreductase, EC 1.11.1.2) and the $\mathrm{NADH}_{2}$ oxidase system. For the dehydrogenation of $\mathrm{NADH}_{2}$ or $\mathrm{NADPH}_{2}$, Kikuchi's method ${ }^{10)}$ of $\mathrm{NADPH}_{2}$ diaphorase $\left(\mathrm{NADPH}_{3}\right.$ : (acceptor) oxidoreductase, EC 1.6.99.1) was adopted, using 2,6-dichlorophenol indophenol, vitamin $\mathrm{K}_{\mathbf{3}}$ and coenzyme $Q_{9}$ as hydrogen acceptors. As for vitamin $\mathbf{K}_{3}$ and coenzyme $Q_{0}, 2 \mu$ moles and $1 \mu$ mole, respectively, were separately dissolved in $0.5 \mathrm{ml}$ methanol, and each $0.05 \mathrm{ml}$ of the methanol solution was added to $3 \mathrm{ml}$ of reaction mixtures.

The enzyme activities were expressed as the oxidation or reduction velocity of substrates (mole/mg protein/hour), from the change of optical density, using a Hitachi EPU-2A spectrophotometer $(d=1 \mathrm{~cm})$.

Protein was determined by the colorimetric method of Lowry et al. ${ }^{11}$ ) for which bovine albumin was used as the standard.

Chemicals. NAD, $\mathrm{NADH}_{2}$ and $\mathrm{NADPH}_{2}$ were purchased from Sigma Chemical Company. Vitamin $\mathbf{K}_{3}$ was purchased from Daiichi-Kogyoseiyaku. Cytochrome $c$ and coenzyme $Q_{9}$ were obtained from Rhizopus oryzae as described in the preceding paper. ${ }^{5)}$

\section{EXPERIMENTAL AND RESULTS}

\section{Respiratory quotient and lactate formation of the mycelia}

Comparative investigations were carried out using the Warburg respirometric technique on the degradation of glucose by the mycelia obtained from surface and shake cultures at various periods of incubation. Typical results are shown in Fig. 1 and Table $I$.

The mycelia of surface cultures demonstrated oxygen uptake, carbon dioxide evolution and lactate formation in an almost constant ratio, regardless of the cultural age. The

\footnotetext{
$7)$ L. Smith, "Methods in Enzymology", Vol. II, Academic Press Inc., 1955, p. 732 .

8) S. Fukui, This Journal, 25, 876 (1961); Symp. Enzyme Chem. Japan, 17, 145 (1962).

9) S. Mizushima and K. Kitahara, This Journal, 28, 344 (1964). 10) G. Kikuchi and E. S. G. Barron, Arch. Biochem. Biophys., 84, 96 (1959).

11) O. H. Lowry, N. J. Rossenbrough, A. L. Forr and R. T. Randall, J. Biol. Chem., 193, 265 (1951).
}

(1) Basal medium (without zinc) Age: $13.5 \mathrm{hr}$.

$22 \mathrm{hr}$.

$30 \mathrm{hr}$.
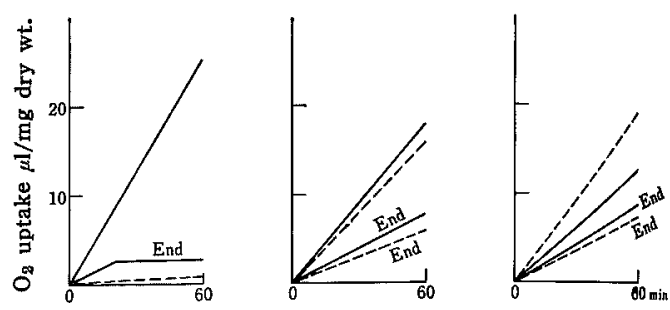

(2) Medium added with $0.4 \mathrm{mg} \mathrm{ZnSO}_{4} \cdot 7 \mathrm{H}_{2} \mathrm{O}$ to $100 \mathrm{ml}$.
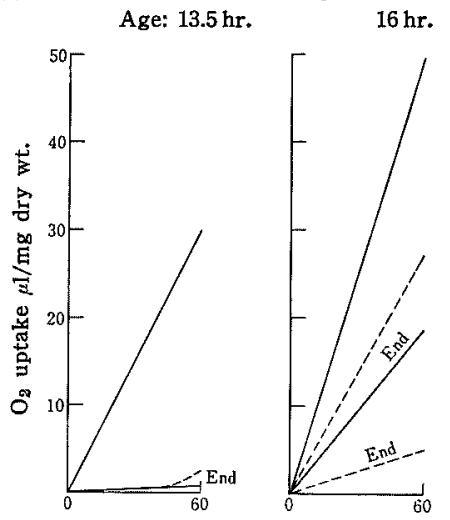
$24 \mathrm{hr}$.

FIG. 1. Change in the Oxygen Uptake $\left(\mathrm{Qo}_{2}\right)$ of Mycelia during the Course of Shake Culture Incubation.

Each Warburg vessel contained $5 \sim 10 \mathrm{mg}$ of mycelia (dry weight), $30 \mu \mathrm{mol}$. of glucose and $0.5 \mathrm{ml}$ of $0.1 \mathrm{M}$ phosphate buffer (pH 6.5). Total volume was brought to $2.5 \mathrm{ml}$ with distilled water:

Reaction temperature: $35^{\circ} \mathrm{C}$.

Broken line: $\mathrm{KCN}$ was added to give the final concentration of $3.3 \times 10^{-8} \mathrm{M}$.

End: endogenous respiration.

respiratory quotient $\left(\mathrm{Qo}_{2}\right.$ (glucose)) was 25 to 30 in the mycelia obtained in the presence of $4.0 \mathrm{mg} \mathrm{ZnSO}_{4} \cdot 7 \mathrm{H}_{2} \mathrm{O}$ per $100 \mathrm{ml}$ medium and 9 to 15 in those obtained without zinc. Moreover, oxygen uptake was activated rather than inhibited by $3.3 \times 10^{-3} \mathrm{M}$ KCN.

On the other hand, younger mycelia from: about 14-hour shake cultures produced a small amount of lactate. Both oxygen uptake and glucose degradation of the mycelia were completely inhibited by $3.3 \times 10^{-3} \mathrm{M} \mathrm{KCN}$. The inhibitory effects of $\mathrm{KCN}$ decreased with in creasing culture age and finally glucose con- 
Table I. Respiration and Lactate Forming Activity of Mycela

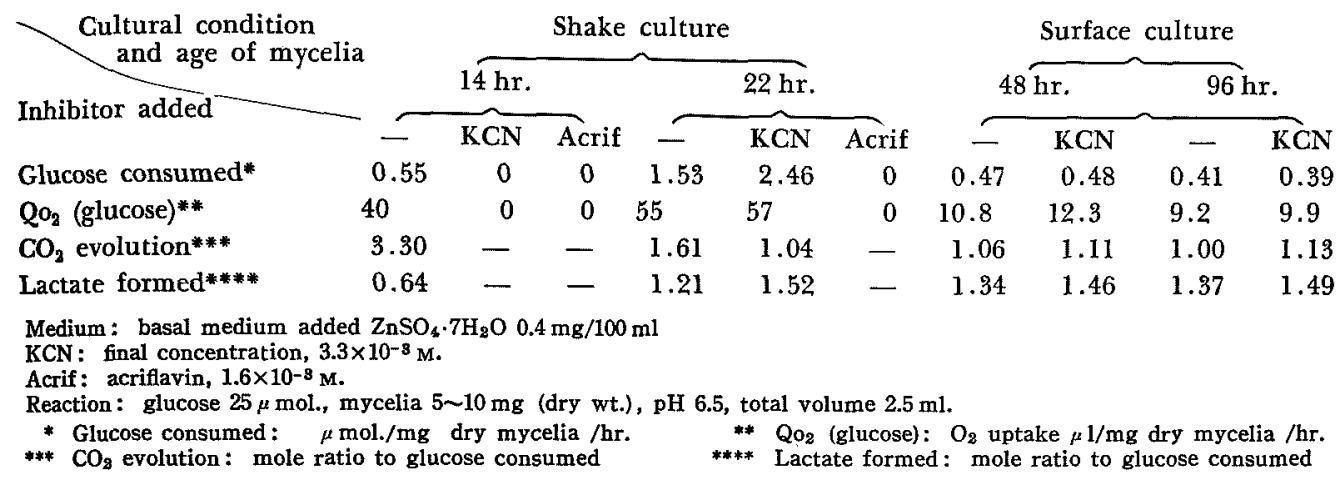

Table II. Hydrogen or Electron Transporting Activities of Cell-free Extracts

$$
\text { Cultural condition and age of mycelia (hr.) } \overbrace{14 \underbrace{}_{22}}^{\text {Shake }} \overbrace{48}^{\text {Surface }}
$$

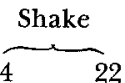

Spectrophotometric assay for enzyme reactions

\section{Reaction}

Cytochrome $\mathrm{c}$ oxidase

$$
\text { " }+\mathrm{KCN}
$$

$\mathrm{NADH}_{2}$ dehydrogenation $\mathrm{H}$-acceptor

Cytochrome c $\left(\mathrm{NADH}_{2}\right.$-cyt c reductase)

2,6-DCIP

Oxygen ( $\mathrm{NADH}_{2}$ oxidase)

Vitamin $\mathbf{K}_{\mathbf{3}}$

Coenzyme $\mathrm{Q}_{9}$

Pyruvate (Lactic dehydrogenase)

$\mathrm{NADPH}_{2}$ dehydrogenation $\mathrm{H}$-acceptor

Cytochrome c (NADPH $\mathrm{N}_{2}$-cyt $c$ reductase)

2,6-DCIP

Vitamin $\mathbf{K}_{3}$

Coenzyme $Q_{9}$

Pyruvate

L-Lactate dehydrogenation $\mathbf{H}$-acceptor

2,6-DCIP (L-lactic dehydrogenase)

$$
\text { " +acriflavin }
$$

Ethanol dehydrogenation $\mathbf{H}$-acceptor

NAD (alcohol dehydrogenase)

Mycelial wt. corresponding to $1 \mathrm{mg}$ protein of extract $(\mathrm{mg})$

$$
\begin{gathered}
\begin{array}{c}
\text { Wavelength } \\
\text { measured } \\
(\mathrm{m} \mu)
\end{array} \\
549(\mathrm{cyt}-\mathrm{c})
\end{gathered}
$$

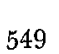$$
340\left(\mathrm{NADH}_{2}\right)
$$$$
\text { "1 }
$$$$
\text { "I }
$$$$
\text { " }
$$$$
"
$$$$
\text { " }
$$$$
549
$$$$
340
$$$$
\text { " }
$$$$
n
$$$$
\text { "l }
$$$$
600
$$$$
\text { (2,6-DCIP) }
$$$$
\begin{array}{r}
0.33 \\
* 0.70
\end{array}
$$$$
1.26
$$$$
1.59
$$$$
2.59-1.39
$$$$
2.10 \quad 1.26
$$$$
\text { , }
$$

$$
-
$$$$
7.31
$$$$
-
$$$$
1.66
$$

Activity of extract $\mu \mathrm{mol} . / \mathrm{mg}$ protein $/ \mathrm{hr}$.

The mycelia used for the preparation of cell-free extract were the same with those of Table I

For the calculation of the activities ( $\mu$ mol./mg protein $/ \mathrm{hr}$.), the following wavelengths and millimolar extinction coefficients were adopted : 19.2 at $549 \mathrm{~m} \mu$ for cytochrome $c$ (difference between the optical densities at $549 \mathrm{~m} \mu$ of reduced and oxidized cytochrome c); 6.22 at $340 \mathrm{~m} \mu$ for $\mathrm{NADH}_{2}$ and $\mathrm{NADPH}_{2} ; 19.1$ at $600 \mathrm{~m} \mu$ for 2,6-dichlorophenol indophenol.

*: Aliquots of another cell-free extract were used for assay of the enzyme activities. 
sumption and lactate formation were markedly activated by $\mathrm{KCN}$. It is noteworthy that the respiratory quotient was increased in the presence of KCN, and oxygen uptake per equivalent of glucose consumed was much lower than that without $\mathrm{KCN}$.

As shown in Table I, oxygen uptake and glucose degradation were completely inhibited in shake culture mycelia by $1.6 \times 10^{-3} \mathrm{M}$ acriflavin. Though not shown in the Table, a similar inhibitory effect by vitamin $\mathrm{K}_{3}(1.2 \times$ $\left.10^{-3} \mathrm{M}\right)$ and 2,4-dinitrophenol $\left(10^{-3} \mathrm{M}\right)$ was observed.

Endogenous respiration of mycelia was increased with increase in culture age, and the ratio of carbon dioxide evolution to oxygen uptake was less than 1 , namely 0.7 to 0.8 , indicating that fatty substances from the mycelia were being oxidized as the substrate of endogenous respiration.

2. Enzymatic activities of the cell-free extract

Various enzyme activities of the cell-free extract are listed in Table II. Although crude cell-free extracts were used for the enzyme assay, it is possible to compare the activities. Remarkable contrast was observed among the activities of cytochrome c oxidase, of $\mathrm{NADH}_{2}{ }^{-}$ cytochrome $\mathrm{c}$ reductase and of lactic dehydrogenase. The first two enzymes demonstrated high activity in the young mycelia of 14-hour shake cultures; while the latter showed high activity in the mycelia of 22-hour shake cultures and in those of surface cultures.

\section{Effect of KCN on the lactate fermentation in shake culture}

Addition of $2 \times 10^{-4} \mathrm{M} \mathrm{KCN}$ to the medium at the beginning of the incubation markedly inhibited the growth of Rhizopus oryzae in shake culture. Therefore, the microorganism was cultured on the shaker in the basal medium supplied with $0.4 \mathrm{mg} \mathrm{ZnSO}_{4} \cdot 7 \mathrm{H}_{2} \mathrm{O}$ per $100 \mathrm{ml}$. Potassium cyanide was added to a broth culture when lactate accumulation began (21 hours) and incubation was continued. These results are shown in Table III. A high yield of lactate was not obtained in this experiment, presumably because of the addition of zinc to the medium. However, the addition of KCN increased the consumption of glucose and the yield of lactate. The highest yield of lactate was obtained at the concentration of $2 \times 10^{-4} \mathrm{M} \mathrm{KCN}$.

\section{DISCUSSION}

Aerobic respiration plays an important part in lactate fermentation by Rhizopus oryzae. However, little was previously known about the respiration in this fungus.

This study has provided evidence that the mycelia of young shake cultures contain more

Table III. Effect of KCN on the Lactate Fermentation in Shake Culture

$\begin{array}{lrrrr}\begin{array}{l}\text { Concentration of KCN added } \\ \text { (after 21 hr. incubation) }\end{array} & - & 1 \times 10^{-4} \mathbf{M} & 2 \times 10^{-4} \mathrm{M} & 5 \times 10^{-4} \mathbf{M} \\ \text { At 21 hr. incubation } & & & & \\ \text { Glucose consumed (mg) } & 1,710 & 1,750 & 1,740 & 1,830 \\ \text { Lactate formed (mg) } & 480 & 540 & 540 & 500 \\ \text { At 45 hr. incubation } & & & & \\ \text { Glucose consumed (mg) } & 3,480 & 3.360 & 4,110 & 3,960 \\ \text { Mycelia (mg) } & 330 & 360 & 314 & 300 \\ \text { Products (mg) } & & & & 2,190 \\ \quad \text { Lactic acid } & 1,590 & 1,760 & 2,520 & 430 \\ \quad \text { Ethanol } & 330 & 390 & 430 & 230 \\ \quad \text { Fumaric acid } & 300 & 260 & 250 & 55.3 \\ \text { Yield of lactic acid (\%) } & 45.6 & 52.5 & 61.2 & \end{array}$


cytochrome c oxidase and $\mathrm{NADH}_{2}$-cytochrome $c$ reductase than older cultures, and its respiration is inhibited by KCN. With aging of the culture the activities of these enzymes fell off and its respiration turned into a $\mathrm{KCN}$ resistant form of respiration, characterized by the accumulation of lactate. From these results, it may be concluded that in the earlier period of shake culture growth, the fungus obtains energy through the cytochrome system functioning in respiration. Respiration via the cytochrome system then is changed to a KCN-resistant respiration, and consequently the accumulation of lactate takes place. This conclusion seems to be supported by the high content of cytochrome $c$ in the younger mycelia of shake cultures, as was described in the preceding paper.1)

Although the results from the Warburg respirometric analysis may be open to question, surface mycelia are taken to respire predominantly through a cytochrome-independent system rather than a cytochrome system, since the respiration which proceeded with glucose degradation was KCN-resistant.

This supposition is in agreement with the results of Terui et al.12) with Aspergillus ory$z a e$, who reported that surface mycelia of the mold react and respire with gaseous oxygen by the flavin system during surface cultivation. On the other hand, the fungus adapts to form the cytochrome system for respiration with oxygen in the submerged condition, and operates predominantly with this system in shake culture.

Rhizopus oryzae seems to behave almost in the same way toward oxygen as Asp. oryzae, except for the phenomenon that Rhizopus oryzae in older shake culture respires predominantly with the system of flavins and does not respire with the cytochrome system. The alternation of the respiratory systems in shake culture may be looked upon as one of the

\footnotetext{
12) G. Terui and N. Konno, Technol. Repts Osaka University, 10, 889 (1960).
}

reasons why Rhizopus oryzae can accumulate large amounts of lactate even in shake culture. In other words, the accumulation of lactate occurs when the fungus respires with the KCN-resistant system; and when the cytochrome system is the predominant form of respiration, the yield of lactate is very low, presumably because glucose consumption decreases and oxygen uptake and carbon dioxide ,evolution per unit of glucose consumed increáse. An oxygen uptake $\left(\mathrm{QO}_{2}\right)$ of from 10 to 25 was found for mycelia of Rhizopus oryzae grown without zinc in shake culture under conditions appropriate for lactate formation. The addition of zinc to the medium increased the oxygen uptake of the mycelia to $40 \sim 60$, which resulted, as shown in Fig. 1, from the KCN-resistant respiration at the later stage of incubation. The increased oxygen uptake for mycelia obtained from zinc containing media corresponds to the increased FMN content in mycelia obtained as described previously ${ }^{1}$ from zinc containing media. However, the addition of zinc to the medium retarded lactate formation. The relatively high oxygen uptake, even if it is KCN-resistant respiration, might be cited as a reason for the decreased accumulation of lactate.

While studying of the effect of zinc on Saccharomyces, Miwa and Ueyama ${ }^{13}$ observed that the oxygen uptake of the yeast grown in the absence of zinc was 10.2 , while that of the yeast grown in its presence was 42.0. The effect of zinc on Rhizopus oryzae was very similar to the result of Miwa and Ueyama.

Coenzyme $\mathbf{Q}_{9}$ obtained from the mycelia of Rhizopus oryzae did not act as a hydrogen acceptor for $\mathrm{NADH}_{2}$ dehydrogenation by cellfree extracts of the mycelia. No recognizable activities of $\mathrm{NADH}_{2}$-oxidase system and $\mathrm{NAOH}_{2}$-peroxidase were observed in the cellfree extract. Therefore, the enzymes which act in the KCN-resistant respiration system 13) D. Miwa and H. Ueyama, J. Fermentation Technol., 38, $299(1960)$. 
are yet to be ellucidated.

Acknowledgements. The authors express their thanks to Prof. K. Kitahara, the University of Tokyo, for his kind guidance and suggestions. The authors wish to thank Dr.
Department of Agriculture, Ottawa, Canada for his help in preparing the manuscript. This work was supported in part by a Grant from the Ministry of Education in Aid of Scientific Research.

E. W. Seitz, of the Food Research Institute, 